\title{
Bond Deterioration of Corroded-Damaged Reinforced Concrete Structures Exposed to Severe Aggressive Marine Environment
}

\author{
Cecielle N. Dacuan (D) and Virgilio Y. Abellana \\ University of San Carlos, Cebu, Philippines \\ Correspondence should be addressed to Cecielle N. Dacuan; 10307530@usc.edu.ph
}

Received 12 September 2020; Accepted 9 February 2021; Published 2 March 2021

Academic Editor: Jose María Bastidas Rull

Copyright (c) 2021 Cecielle N. Dacuan and Virgilio Y. Abellana. This is an open access article distributed under the Creative Commons Attribution License, which permits unrestricted use, distribution, and reproduction in any medium, provided the original work is properly cited.

\begin{abstract}
Cracks lead to a reduction of the bond between concrete and reinforcing steel rebars. A considerable decrease in the bond strength is more dangerous to a structural element's safety than the loss of the cross-sectional steel reinforcement area. The purpose of this study is to evaluate the bond strength of corroded-damaged structures exposed to severely aggressive marine environments. Eighteen (18) cube specimens with dimensions of $200 \mathrm{~mm}$ x $200 \mathrm{~mm}$ were cast. They were reinforced with three (3) different diameters of deformed steel and were grouped as unconfined and confined. The specimen was accelerated under a simulated corrosive environment. The experiment results reveal that the bond strength of concrete and steel reinforcement is susceptible to corrosion levels. The degree of corrosion significantly affects the bond strength of concrete and steel. The bond strength and the average crack width have a strong correlation; a minimal amount of corrosion with a minimum crack width of $0.03 \mathrm{~mm}$ after cracking reduces the bond strength to an unacceptable level. Stirrups confinement has a significant influence on the bond strength; it provides an excellent means to counteract bond loss. The loss of bond directly affects the serviceability and ultimate strength of reinforced concrete structures. There is an exponential relationship between cement and steel reinforcement's bond strength with the serviceability and residual strength of reinforced concrete structures.
\end{abstract}

\section{Introduction}

Corrosion of steel reinforcement is considered one of the main issues in the construction industry $[1,2]$. It is considered the leading cause of the premature deterioration of reinforced concrete structures $[3,4]$ and the most predominant factor affecting the structural deterioration $[5,6]$. Corrosion of steel reinforcement is the major factor that limits the durability and serviceability performance of reinforced concrete structures [7].

The environmental condition where the structures are exposed has been found to have a significant influence on the reliability of the deterioration of reinforced concrete structures [5]. Corrosion is the most frequent and relevant deterioration suffered by reinforced concrete structures, particularly in structures located in an aggressive marine environment [8]. Corrosion of reinforcement in the marine environment usually occurs due to aggressive agents such as chloride ions [9]. A drop in $\mathrm{pH}$ initiates corrosion of rein- forced concrete structures to a level below 11 [5]. According to Zhao and Jin, reinforcing steel rebars are initially protected by a high $\mathrm{pH}$ of $12-14$ of concrete [10]. At $\mathrm{pH}$ values below 12 , a concrete layer that protects the embedded steel reinforcement is destroyed [5]. The exposure of steel reinforcement from deteriorating agents, like chloride in the marine environment, decomposes the steel in its original states, which is rust [1]. These corrosion products lead to the deterioration of reinforced concrete structures, particularly those facilities in ports that are severely exposed to marine environments [5].

According to Kreit et al., steel corrosion of reinforced concrete leads to several major defects, the reduction of steel reinforcement bars and ductility, and the expansion of the corrosion products, which leads to concrete cracking and spalling, then to the deterioration of the bond [11], and reduction of its serviceability and residual strength [12]. It disclosed that the main issue in the degradation of reinforced concrete structures due to corrosion is the reduction of its 
mechanical strength and the reduction of bond strength between concrete and steel reinforcement [13]. A considerable decrease in the bond strength at the steel-concrete interface can be more dangerous to a structural element's safety than the loss of the steel cross-sectional area at the bond interface [14].

The bond between the steel reinforcement and concrete is considered one of the essential properties for reinforced concrete structures [5]. The bond behavior between the reinforcing steel and the surrounding concrete is a significant factor in reinforced concrete structures' structural performance, particularly in terms of serviceability and load-carrying capacity in their remaining service life $[15,16]$. Bonding facilitates load transfer across the steel-concrete interface, essential for the composite action of reinforced concrete structures. Bonding behaviors are primarily dependent on three factors: the compressive strength of concrete, confinement, and the surface of the reinforcing rebars [9].

Corrosion greatly influences the bond mechanism of steel and concrete [17]. The surface of the steel rebar itself is disintegrated, and its ribbed surface is altered. Corrosion products in the form of rust cause expansion in the volume of reinforcing steel. Volume expansion, in turn, exerts internal pressure on the surrounding concrete [3]. The expansion of corrosion products due to steel disintegration leads to spalling and eventually cracking the concrete surface [3, 12]. Cracks are generated on the surface of concrete when the ultimate stresses exceed the tensile strength of concrete. Once a crack has been generated, it propagates widely, which leads to a reduction in confinement between the steel and concrete [12].

Small amounts of corrosion products can reduce the bond strength to unacceptable levels [12]. However, at a certain level of corrosion, there is an increase in friction between the bars and concrete, which leads to a better bond and enhances the strength. The bond strength increases up to a certain level of reinforcement corrosion. However, with a further increase in corrosion, the bond strength progressively declines [9]. The continuous disintegration of steel-concrete bonds reduces the strength and ductility of reinforced concrete structures [18]. If the corrosion is allowed to propagate over a sufficiently long period, and the proper interventions are delayed, loss of the bond between the corroded steel bar and the surrounding contaminated concrete may lead to impaired structural performance and safety of the affected structures [4]. It likewise causes the design life span of the structures to be shortened [17]. Corroded-damaged structures not only give the appearance of poor performance but also can, in extreme cases, lose their structural integrity [18]. Therefore, the limit mass loss of existing corroded steel reinforcement is important in understanding the bond strength behavior of reinforced concrete structures. This will help to determine the appropriateness and effectiveness of the repair to be indulged in corroded structures.

Many structures in harsh marine environments have experienced unacceptable losses in serviceability and safety much earlier than anticipated, owing to the corrosion of reinforcing steel and thus need rehabilitation, strengthening, or replacement [19]. Several studies related to the repair or ret- rofitting of existing corroded-damaged structures have been conducted by many researchers for its rehabilitation or restrengthening. The limit mass loss of corroded structural elements was considered in each method or retrofitting techniques to restrengthen the corroded-damaged reinforcing rebars. Triantafyllou et al. disclosed patch repair and FRP bonded laminates' effectiveness to retrofit corrodeddamaged reinforced concrete beams. The methods' appropriateness and effectiveness were based on the measured mass loss of the deformed reinforcement rebars, which is from $7.56 \%$ to $24.15 \%$ gravimetric mass loss of rebars. Further, the average steel mass losses of $7.56,15.48$, and $24.15 \%$ resulted in maximum longitudinal corrosion-induced crack widths of $0.35,0.90$, and $1.40 \mathrm{~mm}$, respectively [20]. In a similar study, Triantafyllou et al. conducted an experimental and analytical investigation of four reinforced concrete beams with corroded steel reinforcements with a mass loss of around $7.5 \%$. From their assessment, the residual flexural capacity of the corroded beams and the suitable strengthened measures depend largely on the concrete cover crack pattern and width of $0.30 \mathrm{~mm}$. The beams were strengthened with two NSM FRP strips of equivalent axial rigidity with EBR FRP laminate presented an 18.20\% higher load and 41.5\% higher deflection than the latter [21]. Kreit et al. implemented the Near Surface Mounted technique NSM and used a $6 \mathrm{~mm} \varnothing$ CFRP rod to increase corroded beams' loadbearing capacity significantly. The experiment was conducted on a 23-year corroded beam stored in a chloride environment under service loadings. A corroded beam with a $40 \%$ reduction in its steel cross-sectional area was effectively repaired using the NSM techniques. It showed the same ultimate capacity as the control-uncorroded beam [11]. AlSaidy et al. repaired the corroded-damaged structural beams by bonding carbon-fiber-reinforced polymer CFRP sheets to the tension side to restore the strength loss to corrosion. Repaired structural beams have a $5 \%$ to $15 \%$ reduction in their cross-sectional area, which corresponds to their corrosion rates. The corroded beams showed lower stiffness and strength than the control-uncorroded specimens. Its strength was restored to the undamaged state when strengthened with CFRP sheets. The use of CFRP sheets for strengthening corroded RC beams can maintain the structural integrity and increase the ultimate strength of beams to a level above the ultimate strength of the control-uncorroded beams. Furthermore, the use of CFRP sheets for strengthening RC beams decreased the ultimate deflection of these beams to a level below the control-uncorroded beams [19]. This implies that corrosion-damaged structures can be effectively repaired with several mentioned techniques employed by different authors. Its appropriateness and effectiveness rely on the mass loss reduction of steel reinforcement rebars.

It is essential to evaluate the bond strength degradation to predict a corroded reinforced concrete structure [18]. Several studies have been undertaken considering the bond strength of steel and concrete and the methods to be taken for the strengthening or retrofitting of corroded, damaged structures. However, the effects of corrosions on bond strength deterioration are limited, considering the span of life of those structures affected by corrosion exposed to aggressive marine 
environments, especially those of pier wharves whose entire life is at risk of corrosion deterioration.

This study will evaluate the factors that affect the bonding behavior of reinforced concrete structures, particularly the pile-supporting wharves, and will help predict the serviceability and ultimate strength of corroded-damaged structural elements. The purpose of this study is to investigate the relationship between the degree of reinforcement corrosion and bond properties. This study will help in the decisionmaking regarding the maintenance and repairs of corrosion-affected reinforced concrete structures.

Experimental procedures were employed in this study. Corrosion acceleration with the galvanostatic method in an artificially controlled environment was implemented. After a period of accelerating corrosions, the specimens were subjected to several measurements of data.

\section{Materials and Methods}

2.1. Research Flow Chart. The following were carried over during the experimental program: characterization of the materials and variables used in the research, corrosion acceleration method, pull-out testing, and bond stress measurement. Figure 1 shows an overview of the research methodology.

2.2. Specimen Preparation. 18 samples of $200 \mathrm{~mm} \times 200 \mathrm{~mm}$ x $200 \mathrm{~mm}$ cubes were cast and grouped as confined and unconfined. Three (3) different sizes of diameter reinforcements were used in each group, as shown in Table 1. Four (4) additional control specimens were cast from each group of different steel main vertical reinforcement sizes.

The specified compressive concrete strength was $28 \mathrm{MPa}$ during a 28 period. Ordinary Portland cement (ASTM C150 Type I), fine aggregates (medium-sized natural sand), and coarse aggregates were used. Figures 2 and 3 show the gradation curves of the fine aggregates and coarse aggregates, respectively. The ratio of water to cement was considered constant throughout the experiments; it was $0.45 \mathrm{w} / \mathrm{cm}$. It was based on ACI 211, and 0.45 is the maximum permissible water-cement for concrete in severe exposure to seawater. The concrete proportions and mixing are shown in Table 2. Table 3 shows the uncorroded steel reinforcement properties, a control rebar specimen used in the experiments.

2.3. Specimen Geometry. A single reinforcing bar from each group was used and placed in the middle, with a total length of $500 \mathrm{~mm}$ in each cast specimen. Each reinforcement diameter in each group was installed in the center of a cube specimen with a bottom concrete cover of $50 \mathrm{~mm}$ and an embedded length of $150 \mathrm{~mm}$ for all the specimens. For confined specimens, $8 \mathrm{~mm} \varnothing$ deformed bars were used as lateral stirrups. A closed stirrup was provided with a $40 \mathrm{~mm}$ spacing. After $24 \mathrm{~h}$, the cast specimens were demolded and soaked in fresh water. After the first 24hour curing in freshwater, the specimen was air moist for $2-1 / 2$ days. After 28 days of curing, the specimens were subjected to accelerated corrosion. Figure 4 shows the

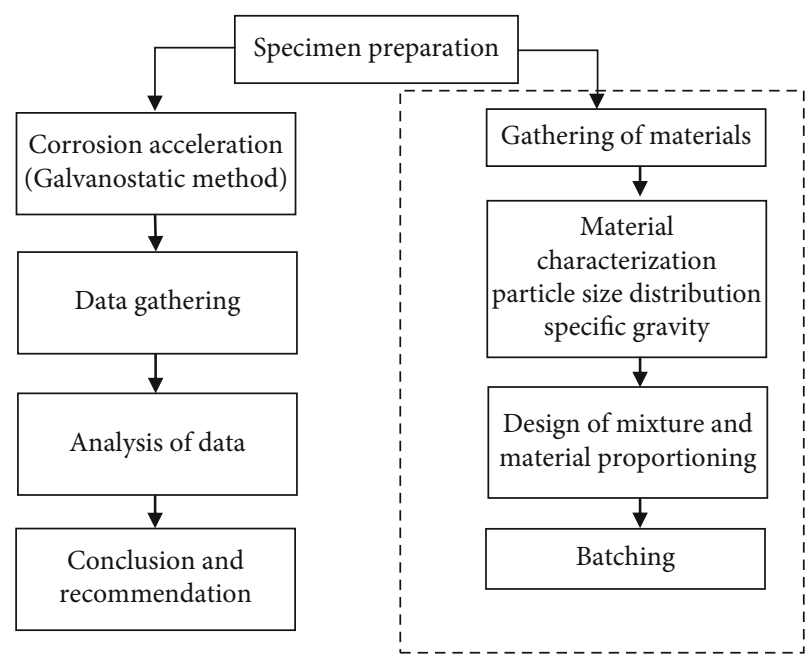

Figure 1: Research flow chart.

specimen's details with confinement, Figure 5 details of the specimen without confinement, and Figure 6 shows the scheme of a prism. Square specimens were cast with square stirrups of $8 \mathrm{~mm}$ diameter to model the specimens more realistically with the actual structures of square piercolumns dimensions.

2.4. Accelerated Corrosion Program. The specimens were corroded using an electrochemical accelerated corrosion technique that involved impressing a current through the specimen. A detailed illustration of corrosion acceleration using impressed current technique is shown in Figure 7. The specimen was immersed in an electrolytic solution containing $5 \%$ sodium chloride $(\mathrm{NaCl})$ solution by weight of water to accelerate the oxidation process. The current was $0.10 \mathrm{~A}$ per specimen, allowing for the required reduction in the cross-sectional area over approximately 360 days. The solution was changed every week to eliminate any change in sodium chloride solution $(\mathrm{NaCl})$. The current direction was arranged so that the reinforcing bar served as the anode, while the steel mesh served as the cathode. A $200 \mathrm{~mA}$ current was applied.

2.5. Testing of Specimen. After the accelerated corrosion, pullout tests were performed on the specimens. The pull-out tests were conducted following a procedure similar to ASTM C234 (ASTM 1988). The testing machine is shown in Figure 8. In these experiments, all specimens' loading was monolithically increased slip loading with a loading speed of $0.40 \mathrm{~mm} / \mathrm{min}$. The corroded specimens were tested in a loading machine with a specially designed and fabricated loading frame. The pull-out tests were performed using a universal testing machine that had a capacity of $50 \mathrm{kN}$. The load was applied at a rate of $2 \mathrm{kN} / \mathrm{s}$ and distributed on the specimen surface by a square steel plate with $20 \mathrm{~cm}$ and a hole at the center. All specimens were tested at the age of 28 days.

2.6. Calculation. The weight of the rebars was tabulated before and after corrosion acceleration. The weight of the 
TABle 1: Specimen designation.

\begin{tabular}{|c|c|c|c|}
\hline Group - $\varnothing(\mathrm{mm})$ & $\begin{array}{c}\text { Specimen ID } \\
\text { No. }\end{array}$ & $\begin{array}{c}\text { Concrete cover } \\
(\mathrm{mm})\end{array}$ & $\begin{array}{l}\text { Dimension } \\
(\mathrm{mm})\end{array}$ \\
\hline \multicolumn{4}{|l|}{ Confined } \\
\hline \multirow{3}{*}{$\mathrm{I}-16 \mathrm{~mm}$} & A-1 & \multirow{18}{*}{50} & \\
\hline & A-2 & & \\
\hline & A-3 & & \\
\hline \multirow{3}{*}{ II $-20 \mathrm{~mm}$} & B-1 & & \\
\hline & B-2 & & \\
\hline & B-3 & & \\
\hline \multirow{3}{*}{ III $-25 \mathrm{~mm}$} & C-1 & & \\
\hline & $\mathrm{C}-2$ & & \\
\hline & $\mathrm{C}-3$ & & $200 \times 200 \times 200$ \\
\hline Unconfined & D-1 & & \\
\hline \multirow[t]{3}{*}{ IV-16mm } & D-2 & & \\
\hline & D-3 & & \\
\hline & E-1 & & \\
\hline \multirow[t]{3}{*}{$\mathrm{V}-20 \mathrm{~mm}$} & E-2 & & \\
\hline & E-3 & & \\
\hline & F-1 & & \\
\hline \multirow[t]{2}{*}{ VI $-25 \mathrm{~mm}$} & $\mathrm{~F}-2$ & & \\
\hline & F-3 & & \\
\hline
\end{tabular}

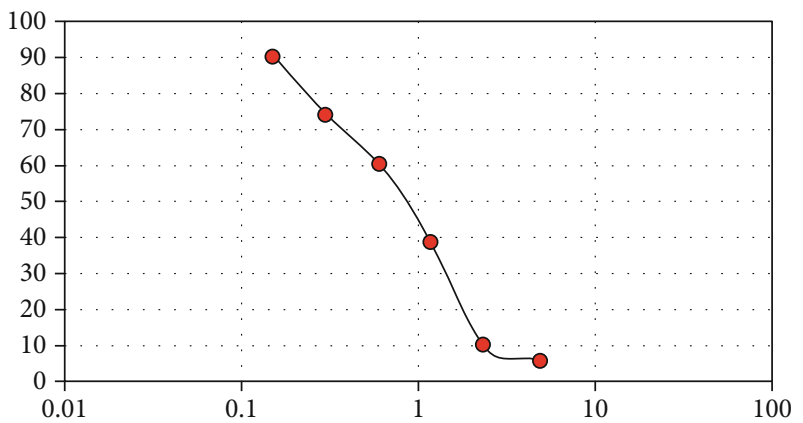

Figure 2: Gradation curves of fine aggregate.

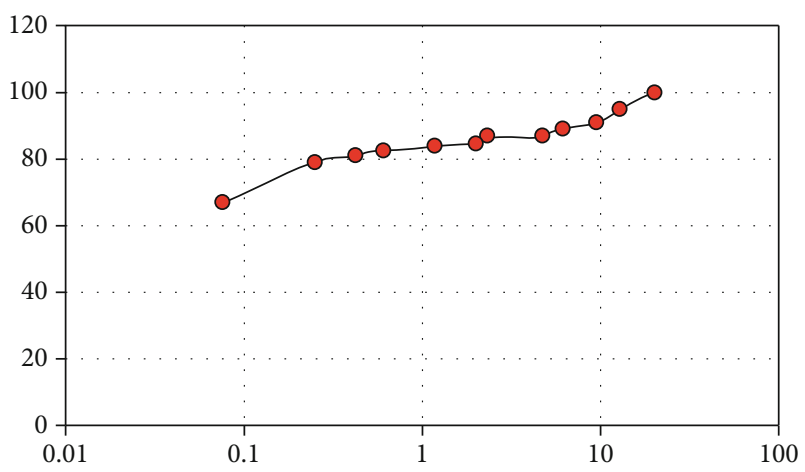

FIgURE 3: Gradation curves of course aggregate.
TABLE 2: Materials proportion of designed concrete mix (unit: $\left.\mathrm{kg} / \mathrm{m}^{3}\right)$.

\begin{tabular}{lcccc}
\hline Cement & $\begin{array}{c}\text { Fine } \\
\text { aggregate }\end{array}$ & $\begin{array}{c}\text { Coarse } \\
\text { aggregate }\end{array}$ & Water & $\begin{array}{c}\text { Water/cement } \\
\text { ratio }\end{array}$ \\
\hline 411 & 783 & 992 & 185 & 0.45 \\
\hline
\end{tabular}

TABle 3: Properties of the control-reinforcing rebars.

\begin{tabular}{lcccc}
\hline $\begin{array}{l}\text { Diameter of } \\
\text { rebars }(\mathrm{mm})\end{array}$ & $\begin{array}{c}\text { Tensile } \\
\text { strength } \\
\mathrm{MPa}\end{array}$ & $\begin{array}{c}\text { Yield } \\
\text { strength } \\
\mathrm{MPa}\end{array}$ & $\begin{array}{c}\text { Ultimate } \\
\text { strain }\end{array}$ & $\begin{array}{c}\text { Elastic } \\
\text { modulus } \\
\mathrm{MPa}\end{array}$ \\
\hline 16 & 663.50 & 248.68 & 0.078 & \\
20 & 662.30 & 286.48 & 0.098 & $200 \times 10^{6}$ \\
25 & 827.87 & 305.58 & 0.122 & \\
\hline
\end{tabular}

actual corroded bars and area reduction was determined using the given formula:

$$
A_{c s}=W_{f} /\left(L \times \gamma_{\text {iron }}\right),
$$

where:

$A_{c s}=$ actual area of corroded reinforcement bar $\left(\mathrm{mm}^{2}\right)$,

$W_{f}=$ weight of reinforcement after corrosion, and rust removed $(\mathrm{g})$

$L=$ length of the specimen $(\mathrm{mm})$ and

$\gamma_{\text {iron }}=0.00785 \mathrm{~g} / \mathrm{mm}^{3}$ (steel).

The actual mass of rust per unit surface area following ASTM G1 on rebars extracted from the concrete specimen after the accelerated corrosion test is computed as

$$
M_{a c}=\frac{\left(W_{i}-W_{f}\right)}{\pi D L}
$$

where:

$M_{a c}=$ actual mass of rust per unit surface area of the bar $\left(\mathrm{g} / \mathrm{cm}^{2}\right)$,

$W_{i}=$ initial weight of the bar before corrosion $(\mathrm{g})$,

$W_{f}=$ initial eight after corrosion (g) for a given duration of induced corrosion,

$D=$ diameter of the rebar $(\mathrm{cm})$, and

$L=$ length of the rebar sample $(\mathrm{cm})$.

Rate of corrosion was determined using corrosion current density, $i_{\text {corr }}$ :

$$
i_{c o r r}=\frac{M_{a c} F}{E W t}
$$

where:

$i_{\text {corr }}=$ corrosion current density $\left(\mu \mathrm{Amp} / \mathrm{cm}^{2}\right)$,

$M_{a c}=$ actual mass of rust per unit surface area of the bar $\left(\mathrm{g} / \mathrm{cm}^{2}\right)$,

$F=$ Faraday's constant (96487 Amp-sec),

$E W=$ equivalent weigth of steel (27.925 for steel), and

$\mathrm{T}=$ time of accelerating corrosion (sec). 


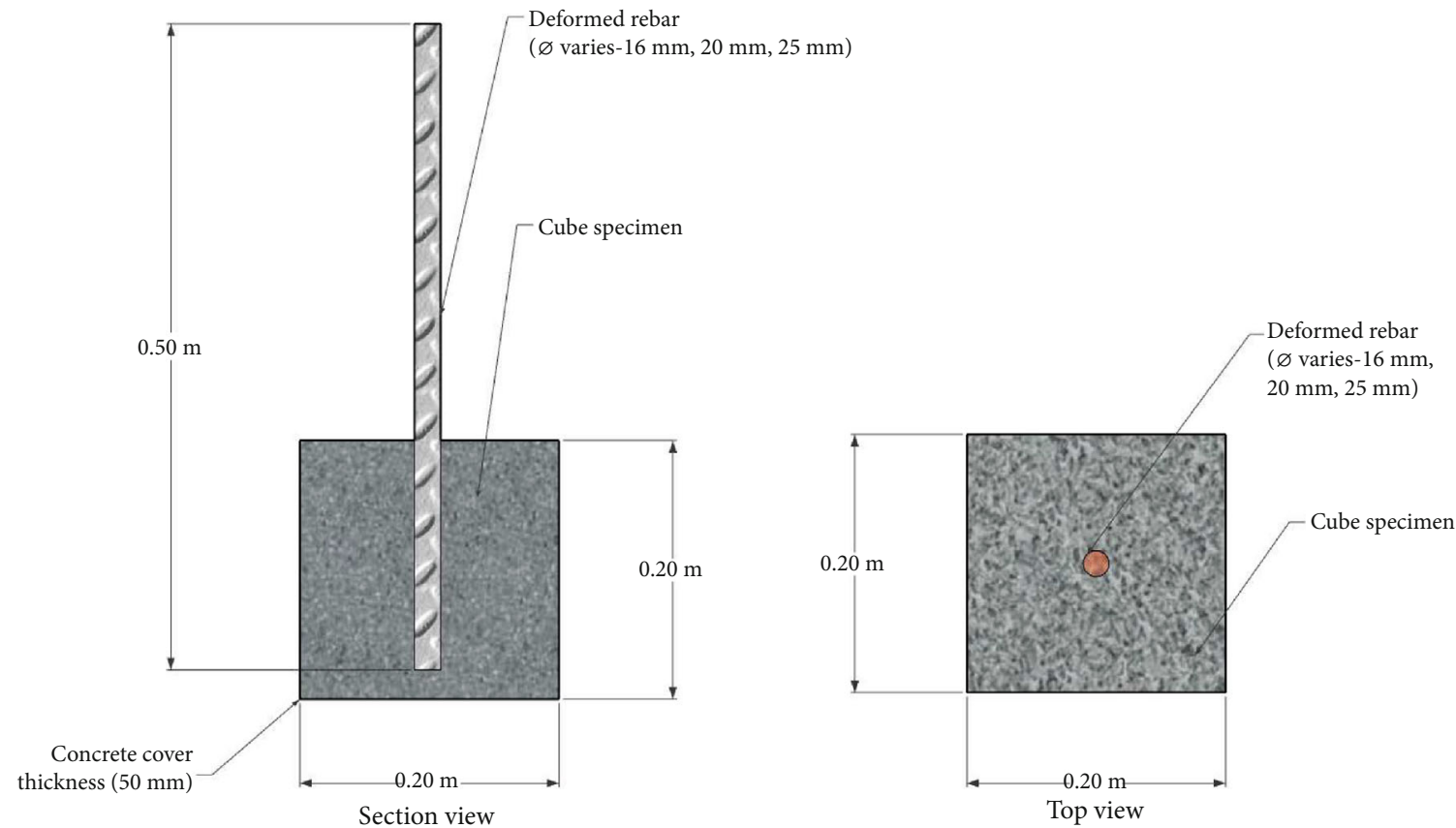

Figure 4: Detail of specimen with unconfinement.

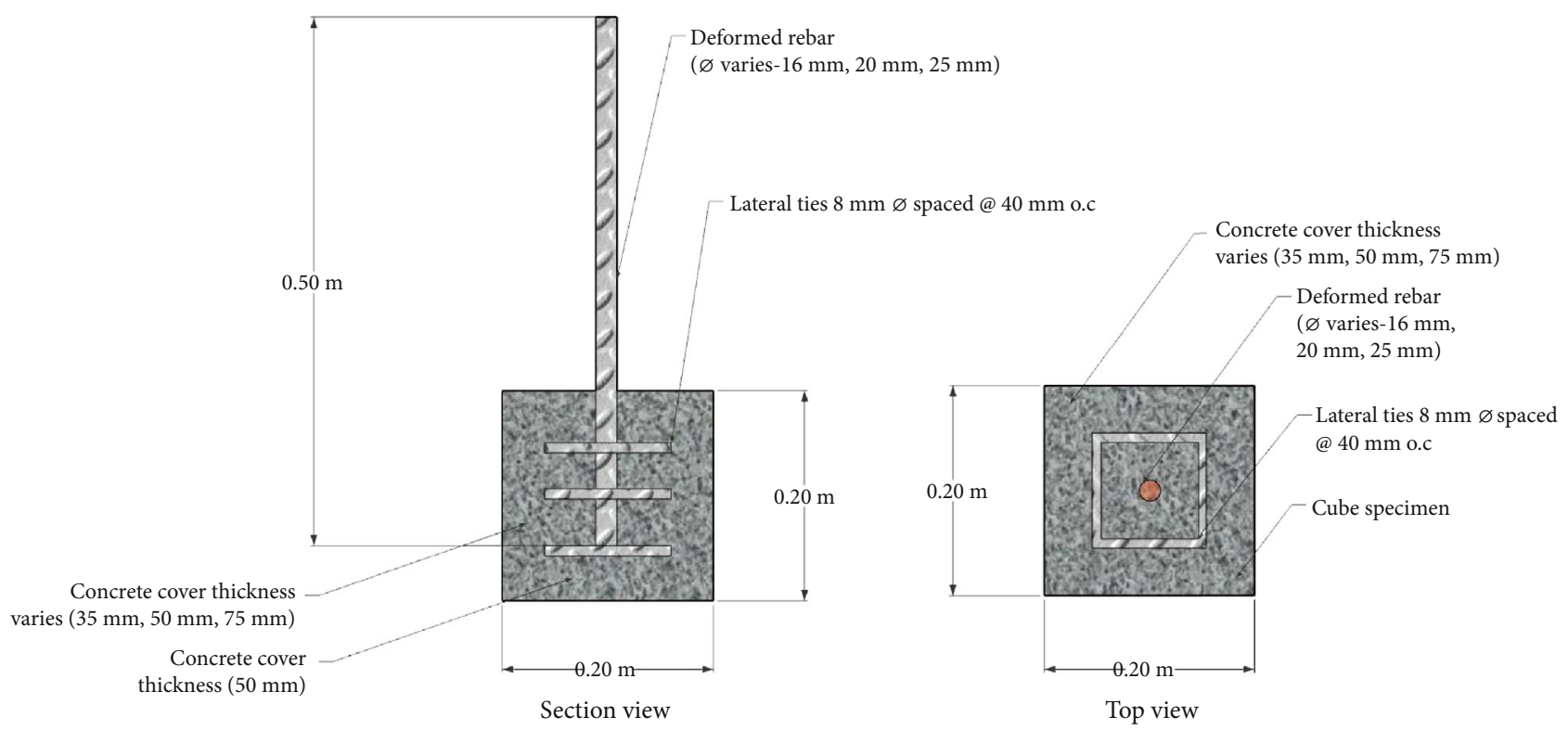

FIgURE 5: Detail of specimen with confinement.

The corrosion level is expressed using the equation:

$$
C_{r}=\frac{G_{0}-G}{g_{n} L} \times 100 \%,
$$

where:

$G_{\mathrm{o}}=$ is the initial weight of the embedded part of steel reinforcement covered by concrete, before corrosion;
$G=$ is the weight of the embedded part of the steel reinforcement covered by concrete, after removal of the corrosion products;

$g_{0}=$ is the weight per unit length of the embedded steel reinforcing bar covered by concrete; and

$L=$ is the bond length and length of the embedded steel reinforcing bar covered by concrete.

2.7. Bond Stress Calculations. Bond stress is calculated as the average stress between the reinforcing bar and the 


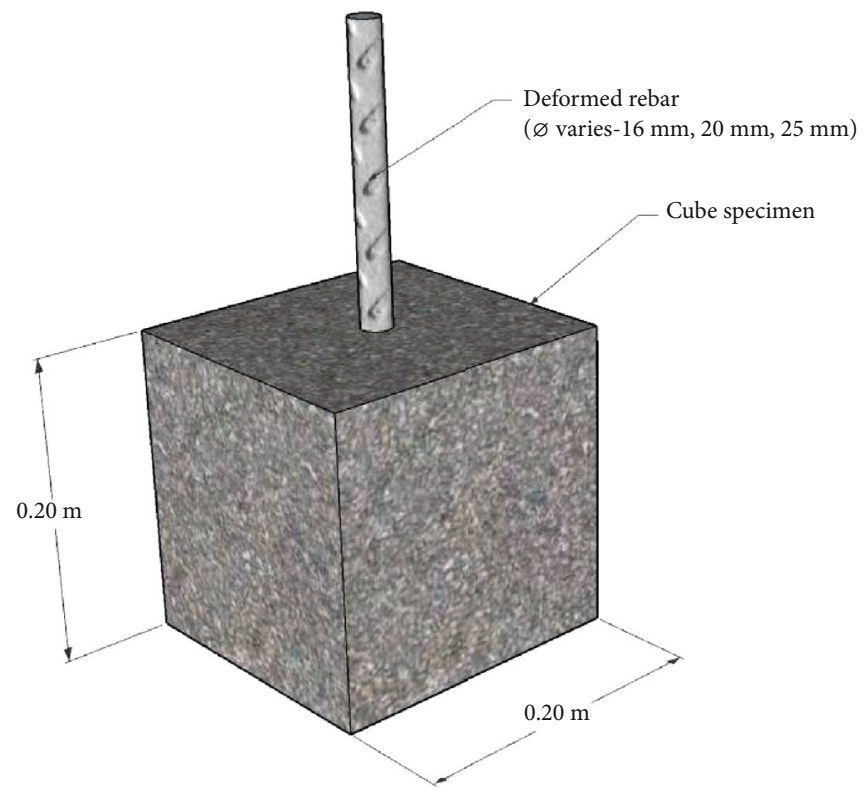

Figure 6: Scheme of cube specimen.

surrounding concrete along the bar's embedded length. In general, the bond stress corresponding to the maximum pull-out load can be regarded as the bond strength or the ultimate bond. The criterion of ultimate bond strength is characterized by its clear definition and simplicity in bond strength interpretation. For uniform bonds, the bond stress can be expressed as $[9,22]$

$$
\tau=F_{\max } /(\pi \times L \times d)
$$

where:

$$
\begin{aligned}
& \tau=\text { bond stress }(\mathrm{MPa}), \\
& F_{\max }=\text { Maximum pull out load, } \\
& D=\text { diameter of the bar, and } \\
& L=\text { embedded bar length. }
\end{aligned}
$$

\section{Results and Discussion}

The following discusses the correlations of the properties of the corroded specimens. Table 4 shows the properties of the corroded specimens.

Specimens were grouped into unconfined and confined groups. Unconfined are specimens without stirrups reinforcements, while confined are specimens with $8 \mathrm{~mm} \emptyset$ stirrups, as shown in Figures 4 and 5, respectively. In each group, three (3) different diameters of deformed steel reinforcement were used: $16 \mathrm{~mm}, 20 \mathrm{~mm}$, and $25 \mathrm{~mm}$. Additionally, six (6) units of specimens were cast in each steel reinforcements group of different sizes as control specimens. Specimen IDs A-0, B-0, and C- 0 were the control specimens for unconfined groups with $16 \mathrm{~mm}, 20 \mathrm{~mm}$, and $25 \mathrm{~mm}$ diameter, respectively. Simultaneously, D-0, E-0, and F-0 were the control specimens for the confined group with $16 \mathrm{~mm}, 20 \mathrm{~mm}$, and $25 \mathrm{~mm}$ diameter, respectively. Specimen ID I-16 is in the unconfined group with $16 \mathrm{~mm}$ diameter. Three (3) specimens were cast designated as A-1, A-2, and A-3: for confined groups: IV-16 with D-1, D-2, and D-3; V-20 with E-1, E-2, and E-3; and VI-25 with F-1, F-2, and F3. All confined specimens had a concrete cover thickness of $50 \mathrm{~mm}$ clear distance. All concrete specimens reinforced with steel rebars were accelerated with the same corrosion acceleration of the impressed current techniques and the same duration.

In each group with different specimen IDs, crack widths were observed and tabulated. The weight of each specimen was recorded before accelerating corrosion. After a year of accelerating corrosion procedures, specimens were removed from the covered concrete. After extracting the steel rebars from concrete, the steel specimens were immersed in hydrochloric acid for $10 \mathrm{~min}$, as required by ASTM G1 (2011), and later with potable water. The specimens were further cleaned with a bristle brush. After being subjected to cleaning, the steel reinforcements were weighed to determine the corrosion it accumulated. The initial weight of the embedded part of the steel reinforcement with concrete before corrosion accelerations was tabulated and the weight after the acceleration of corrosion. The corrosion level (\%) was determined using Equation (4), considering each specimen's weight before and after the corrosion acceleration procedures. The length of the embedded reinforcement, which was actually covered by concrete, was considered when determining its weight using a digital weighted scale with 0.01 accuracy. The actual area of steel reinforcement after cleaning was determined using Equation (1). The corroded steel reinforcement's actual weights were used in the calculation of the actual area of corroded rebars. From the calculated actual area of corroded steel reinforcement, the area reduction of each steel vertical reinforcement was determined by deducting from the uncorroded weight of steel reinforcement (control specimen) of similar diameter and length. The actual mass of rust per unit surface area was determined using Equation (2). From the tabulated weights of the steel reinforcements, before and after the corrosion accelerations, the 




FIgURE 7: Illustrations of accelerating corrosion of specimens.
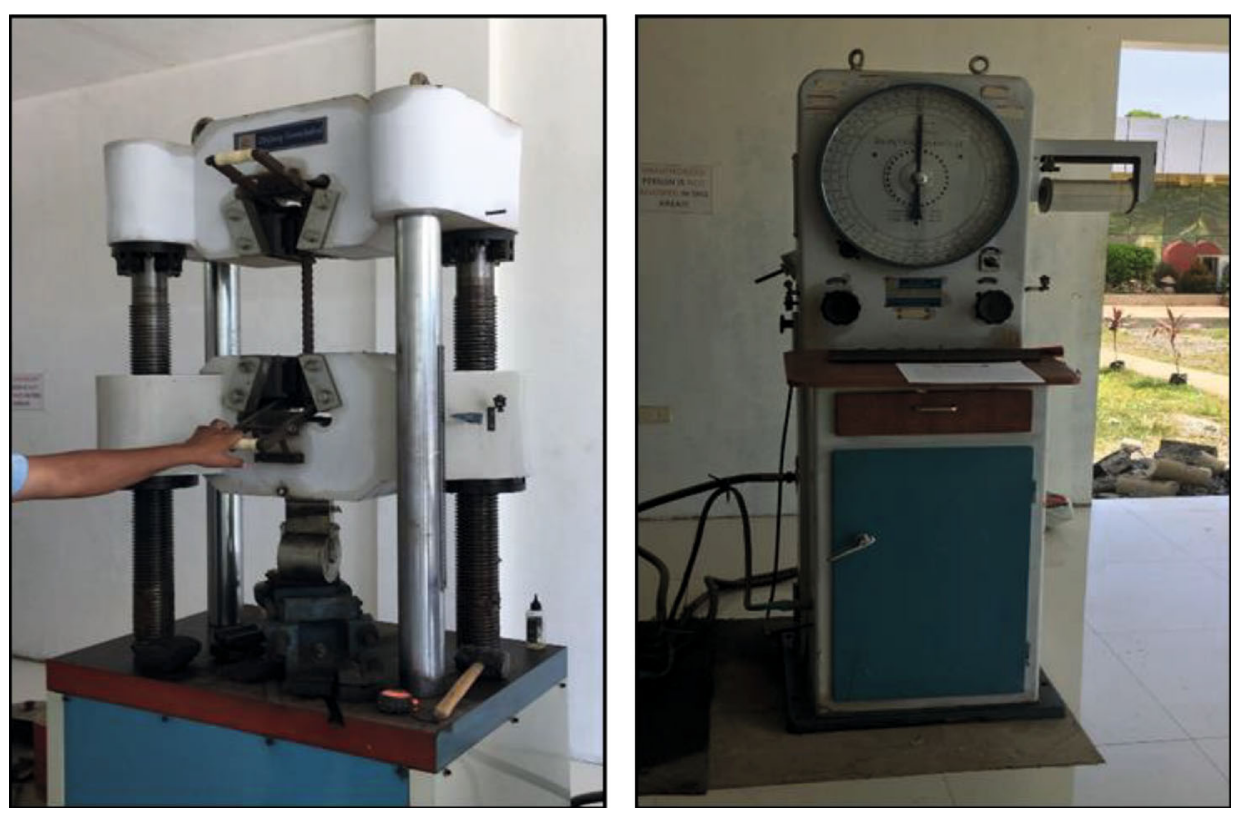

FIgURE 8: Pull-out testing machines.

corrosion rates of each specimen were determined using Equation (3), with each actual mass of rust per unit surface area, and considering the duration in seconds of accelerating corrosions. Bond stress was determined using Equation (5), with a maximum pull-out load of $50 \mathrm{kN}$. The length of the bars considered in the bond strength test is the rebars' embedded length with concrete. The loss in strength (\%) is the difference in the bond strength of the uncorroded rebar specimens and the steel reinforcement's actual bond strength after corrosion acceleration.
3.1. Bond Stress. The diameter of the steel rebars and confinement are two important factors that influence the specimen's bond strength behavior due to corrosion. As verified in Table 4, corrosion significantly causes a reduction of the bond between the concrete and steel reinforcement surface. Control specimens from both groups, A-0, B-0, C-0, D-0, $\mathrm{E}-0$, and F-0, have bond strength of $6 \mathrm{MPa}, 13 \mathrm{MPa}, 17 \mathrm{MPa}$, $21 \mathrm{MPa}, 24 \mathrm{MPa}$, and $30 \mathrm{MPa}$, respectively.

According to Kivell et al., the bond performance is primarily dependent on factors: concrete compressive strength, 


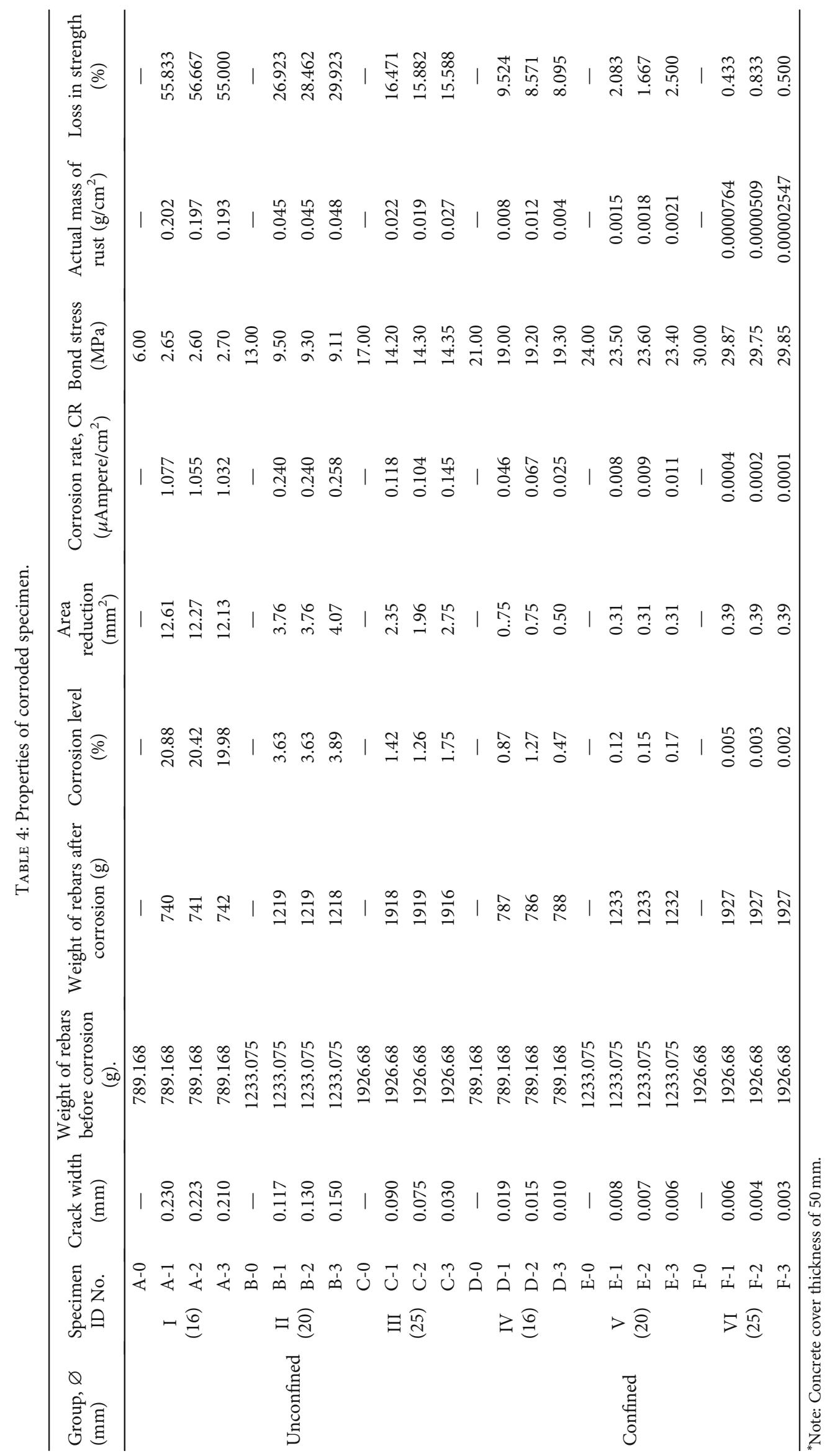




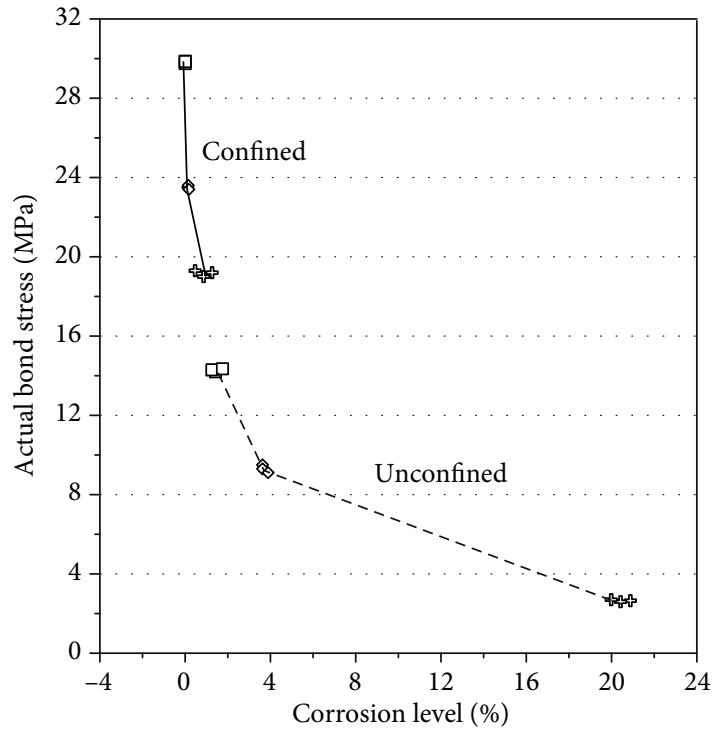

Diameter of deformed steel bars:

\& $16 \mathrm{~mm}$ dia.

$\diamond 20 \mathrm{~mm}$ dia.

$\square 25 \mathrm{~mm}$ dia.

Figure 9: Correlation of bond stress and corrosion level.

confinement, and the surface of the bar (deformed or round) [23]. Confinement provides an excellent means to counteract the bond loss. The presence of stirrups as confinement can significantly limit the degradation of the bond strength [22]. It increases the bond strength of corroded steel rebars $[14,18]$. As verified in Figure 9, the confined group has a higher bond strength than the unconfined group. The bond stress of the same diameter reinforcement is higher in the confined group than in the unconfined group of specimens-specimen in $16 \mathrm{~mm}$ diameter. Unconfined UCF group has a bond stress of $2.65 \mathrm{MPa}$ to $2.70 \mathrm{MPa}$, while the $16 \mathrm{~mm}$ confined CF group has a bond stress of $19 \mathrm{MPa}$ to 19.30 MPa, an almost $85 \%$ of bond strength difference.

Further, Figure 9 shows that, as the level of corrosion increases, the bond stresses between the steel and cement decrease in both the confined and unconfined groups of steel specimens. The correlation between the bond stress and corrosion level is inversely related. According to Chen and Nepal, the bond strength increases at the early stage of corrosion, usually less than $1 \%$ of steel mass loss, but significantly decreases when cracks are generated on the concrete cover surface and then gradually decays to zero [15]. Bond efficiency is evaluated in the presence of an increased corrosion level up to $20 \%$ of mass loss [4]. According to Kivell et al., a low level of corrosion, that is, less than $5 \%$ of steel bar reduction, has a good bond strength; however, with corrosion levels above this, the bond capacity dropped off significantly. Furthermore, according to Ouglova et al., with low corrosions, the bar's surface becomes rougher, which increases the friction between the bar and concrete. At $0.36 \%$ corrosion levels, it creates an opening normal to the interface. When the corrosion levels reach $0.40 \%$, the maximal average bond stress decreases quickly to become negligible. The debonding of concrete and cement is at $0.76 \%$ level of corrosion [6]. It



$\begin{array}{ll}\text { Diameter of steel rebars } & \\ \circ 16 \mathrm{~mm} \text { dia. UCF } & * 16 \mathrm{~mm} \text { dia. CF } \\ \diamond 20 \mathrm{~mm} \text { dia. UCF } & \triangle 20 \mathrm{~mm} \text { dia. CF } \\ \square 25 \mathrm{~mm} \text { dia. UCF } & \approx 25 \mathrm{~mm} \text { dia. CF }\end{array}$

Figure 10: Loss of bond strength due to corrosion level.

should be noted that a low level of corrosion can result in a slight increase in bond strength, but increasing the corrosion level leads to a reduction in the bond between concrete and steel reinforcement. The increase in pressure between the concrete and steel with corrosion products' appearance may contribute to the decrease in the residual bond stress when the corrosion level is high. The bond strength initially increases with an increase in the corrosion level until concrete cracks develop; then, the bond strength decreases with further increases in the corrosion level.

Corrosion levels produced a severe deficiency in bond strength [8]. Smaller reinforcement has a higher corrosion level. It has a higher risk of detachment from its bond with cement, and it has lower bond stress. The smaller reinforcement diameter $(16 \mathrm{~mm})$ had the highest corrosion level and lower bond strength in both groups than the larger reinforcement diameter $(20 \mathrm{~mm}$ and $25 \mathrm{~mm})$. A high corrosion level signifies lower stress between the bonds of cement and steel reinforcement. This reveals that the bond strength measured in the pull-out specimens is significantly affected by the level of corrosion.

When rebar starts to corrode, a gradual decrease in its diameter (axisymmetric corrosion is assumed) is produced, together with the generation of rust. From the graph in Figure 10, the loss of bond strength is higher with the unconfined group of the specimen, while for those in the confined group, the loss of its bond strength is low. Verified from the same figure, a smaller reinforcement diameter $(16 \mathrm{~mm})$ has a great reduction in its strength compared to larger reinforcement diameters $(20 \mathrm{~mm}$ and $25 \mathrm{~mm})$ in both confined and unconfined groups of specimens. For specimens with the same diameters, the unconfined group has a great percentage of its bond strength reduction. In contrast, confined groups have lower bond strength reduction. I-UCF $(16 \mathrm{~mm})$ has a 


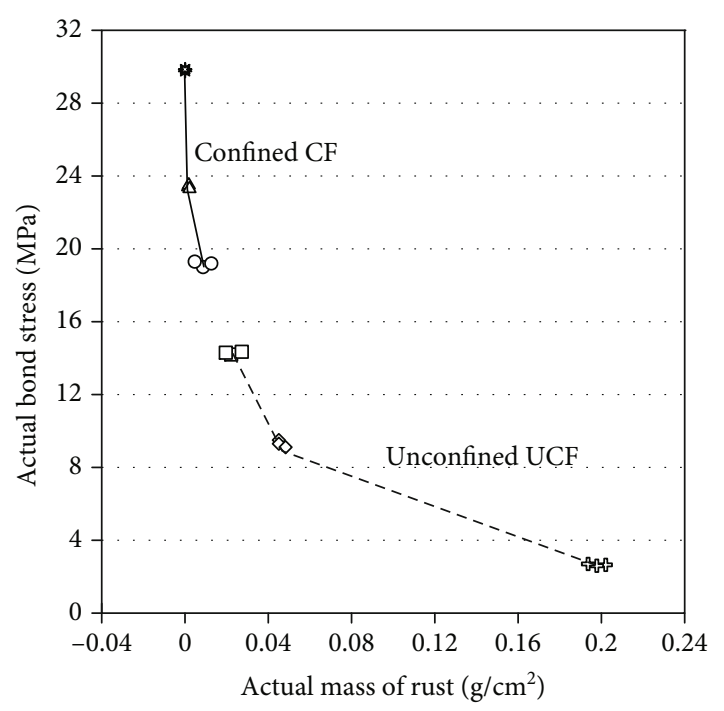

Diameter of steel rebars with group

$$
\begin{array}{ll}
\lessgtr 16 \mathrm{~mm} \text { dia. UCF } & \circ 16 \mathrm{~mm} \text { dia. CF } \\
\diamond 20 \mathrm{~mm} \text { dia. UCF } & \triangle 20 \mathrm{~mm} \text { dia. CF } \\
\square 25 \mathrm{~mm} \text { dia. UCF } & * 25 \mathrm{~mm} \text { dia. CF }
\end{array}
$$

FIGURE 11: Bond strength and mass of corrosion products.

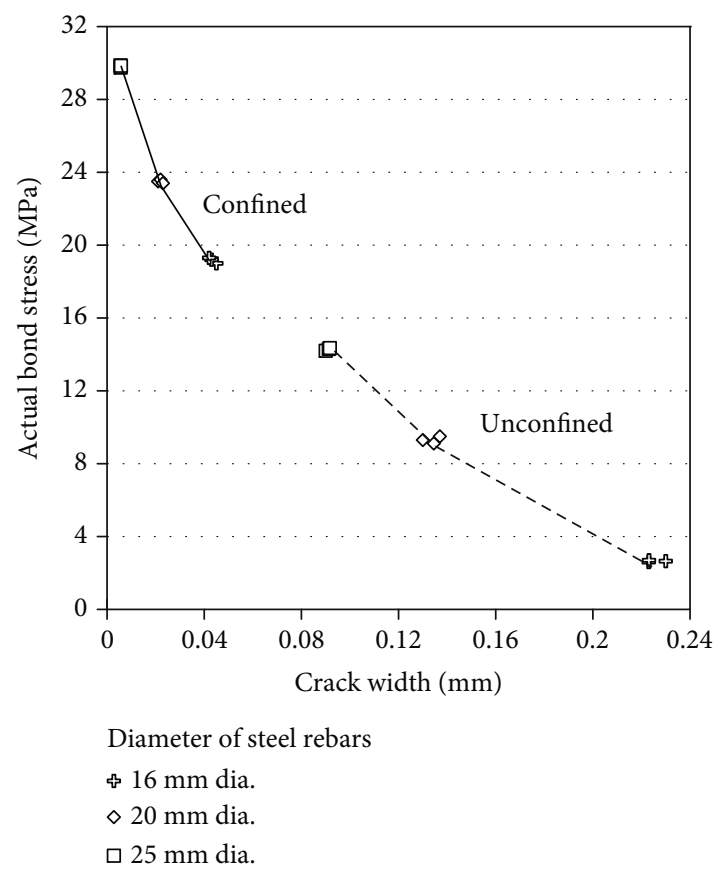

FIGURE 12: Correlation of crack width and bond stress.

$55.83 \%$ loss of its strength, while IV-CF $(16 \mathrm{~mm})$ of the same diameter as I-UCF has a $9.52 \%$ loss of its strength only.

According to Hamidun et al., the pressure created from an $8 \mathrm{~mm}$ steel bar diameter is higher than the pressure of $10 \mathrm{~mm}$ diameter at the same degree of corrosion [1]. With further corrosion, the bond stress declines consistently until it becomes negligible for about 8.50, 7.50, and 6.50\% corrosion for the 10, 14, and $20 \mathrm{~mm}$ bars, respectively [5].

The graph in Figure 11 shows that when the amount of corrosion products increases (actual mass of rust), its bond

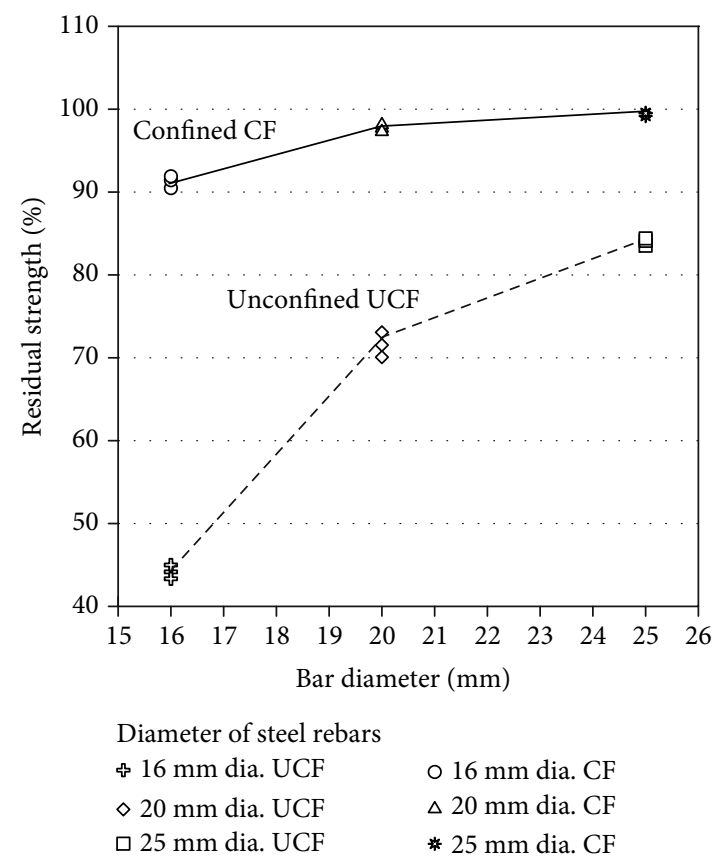

FIGURE 13: Correlation of bar diameter and residual strength.

strength decreases. A linear correlation was applied in both groups, unconfined and confined. Unconfined groups accumulated higher amounts of corrosion products compared to confined groups. Confined groups have higher actual bond stresses. This is due to the horizontal stirrups, which adds up as additional strength protection to the main vertical stirrups, directly facing contact with the cement. Figure 11 reveals that, with the corrosion product or rust to the concrete surface, the bond between the concrete and steel decreases. Corrosion products of steel rebars are the primary factors that affect the debonding between concrete and steel. $0.20 \mathrm{~g} / \mathrm{cm}^{2}$ mass of rust will cause a reduction of $55.83 \%$ of its bond strength. An increase of mass of rust with $1.15 \%$ causes a $1.47 \%$ of reduction of its strength.

3.2. Crack Width. The three phases for bond strength evolution associated with concrete crack development are crack initiation at the bond interface, crack propagation through the concrete cover, and completely cracked over the cover [15]. The crack initiation phase is relatively short; as the corrosion progresses, cracks propagate from the bond interface to the concrete cover surface. With further corrosion, cracks widened until it reached the ultimate cohesive width and the bond strength loses completely.

Figure 12 shows that the confined group of the specimen has the narrowest crack widths. In contrast, the unconfined group has the widest crack width. Bond stress was higher in the confined group and lowered in the unconfined group. The confined group had a crack width of $0.0057 \mathrm{~mm}$ to $0.045 \mathrm{~mm}$ and bond stress of $19 \mathrm{MPa}-29.87 \mathrm{MPa}$. The unconfined group had a crack width of $0.090-0.230 \mathrm{~mm}$ and bond stress of $2.60 \mathrm{MPa}$ to $14.35 \mathrm{MPa}$. From the two lines, it shows that bond stress is inversely correlated with crack width. With an increase in the crack widths, the bond 


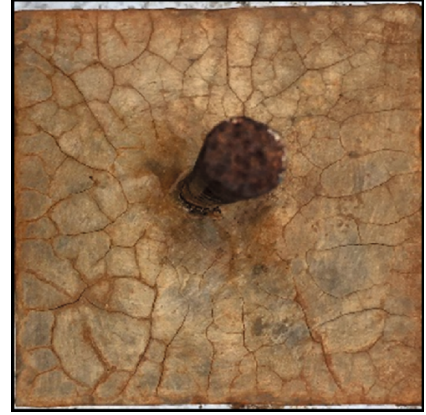

(a)

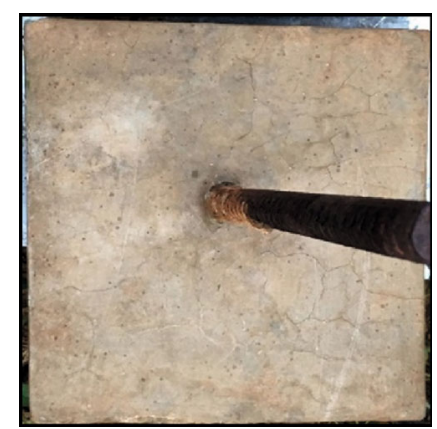

(b)

FIGURE 14: Cracks at (a) unconfined specimen and (b) confined specimen, with $16 \mathrm{~mm}$ diameter vertical reinforcement.

stress also decreases. The results reveal that cracks' width has a high correlation with the bond stress exerted by corrosion products at the interface between the steel reinforcement and concrete. The width of concrete cracks induced by corrosion has an approximately linear relation with the corrosion level [15].

The reinforcement's diameter likewise affects the generation of cracks at the surface of the concrete cover of corroded reinforced concrete structures. A smaller reinforcement diameter $(16 \mathrm{~mm})$ was obtained with wider crack widths than larger reinforcement diameters $(20 \mathrm{~mm}$ and $25 \mathrm{~mm})$. The latter has lower bond stress. Higher corrosion levels exerted a greater amount of corrosion to the interface between the steel and concrete, which causes the creation of wider cracks on the surface of the concrete.

Corrosion products' formation will exert stresses on the concrete-steel interface, which causes cracking and affects its bond behavior. Corrosion cracking is of critical importance from the standpoint of bond strength. The effects of corrosion on the bond signify that as long as there is no cracking of the steel cover, the corroded bar's bond strength increases. However, very little corrosion after cracking can reduce the bond strength to an unacceptable level. A strong correlation exists between the bond strength and the average crack width.

There is an exponential relationship between the bond strength and the average crack width for the specimen without stirrups confinement. For samples with stirrups, the strength showed no reduction until the crack width reached $0.0060 \mathrm{~mm}$. Thus, the surface crack width is a better indicator of bond strength degradation than the average corrosion penetration. According to Lin et al., the bond strength decreases exponentially with the surface crack width [22]. For specimens without stirrups, the bond strength drops significantly with an increase in the crack width. However, for a specimen with stirrups, bond deterioration is prevented by the presence of stirrups.

3.3. Residual Strength. The assessment of the progressive degradation of the bond between concrete and reinforcing steel is of vital importance in evaluating the residual strength of corroded-damaged structures. Cracking the concrete cover due to corrosion may not indicate the end service life of the structures. The cracked member may continue to be in ser-

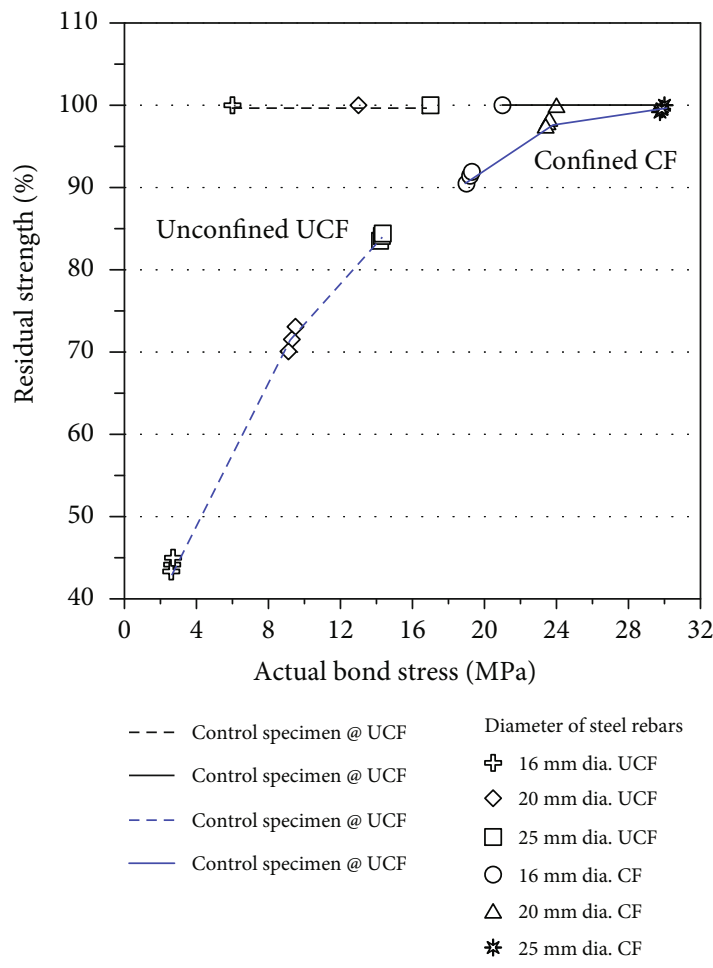

FIgURE 15: Variation of bond stresses.

vice provided that the residual strength is still sufficient to resist the loads within an acceptable margin of safety. The flexural capacity, serviceability, ultimate limit states, and shear capacity are affected by the bond between the steel reinforcement and the adjacent concrete in reinforced concrete structures. The deterioration of the steel-concrete bond due to the steel reinforcement's corrosion causes an increase in deflection and a reduced strength, which leads to failure.

As verified in Figure 13, the specimen's confined group has a higher residual strength compared to the unconfined specimen group. These results are consistent for all sizes of steel reinforcement. In $16 \mathrm{~mm}$ diameter, the unconfined group I-UCF has a maximum of $45 \%$ of its residual strength. In contrast, the confined group IV-CF has a $91.90 \%$ of its residual strength. For a $20 \mathrm{~mm}$ diameter, the unconfined group II-UCF has $73.08 \%$ of its residual strength. In contrast, 
the confined group V-CF has $97.92 \%$ of its residual strength. For a $25 \mathrm{~mm}$ diameter, the unconfined group III-UCF has $84.41 \%$ of its residual strength. In contrast, the confined group VI-CF has $99.57 \%$ of its residual strength. Therefore, confinement has great advantages in the residual life of corroded-damaged structures. Aside from its service of controlling the formation of cracks, stirrup confinement likewise helps maintain the reinforced concrete element's strength. According to Chen and Nepal, stirrup confinement significantly contributes to the ultimate binding strength, specifically the residual bond strength during the residual life phase of corroded reinforced concrete structures [15].

Figure 14(a) shows the specimen from the unconfined group with $16 \mathrm{~mm}$ diameter reinforcement with cracks formed at the concrete surface, and Figure 14(b) shows cracks formed in the specimen from the confined group with $16 \mathrm{~mm}$ diameter reinforcements.

Figure 14 shows cracks formed at the unconfined group of the specimen with $16 \mathrm{~mm}$ diameter and from the confined group of the specimen with $16 \mathrm{~mm}$ diameter at main vertical reinforcement. Each crack was measured and tabulated with a crack ruler's aid, as shown in Table 4 . Unconfined concrete specimen has wider cracks opening of $0.230 \mathrm{~mm}, 0.223 \mathrm{~mm}$, and $0.210 \mathrm{~mm}$, compared to confined concrete specimen with cracks opening of $0.019 \mathrm{~mm}, 0.015 \mathrm{~mm}$, and $0.010 \mathrm{~mm}$. Cracks were measured at every acceleration duration. After a period of 1 year, cracks were tabulated before extracting from the concrete. Steel reinforcement was removed from each covering concrete and subjected to cleaning before subjected to pull-out testing.

Figure 15 shows the variation of bond stresses of each specimen of different reinforcement diameters and different groups. Confined specimens have higher actual bonds with higher residual strength. In contrast, unconfined specimens have lower actual bond stresses and residual strength. The above figure illustrates that stirrup confinement helps increase the residual life of the corroded, damaged reinforcement and secures the corroded, damaged structures' serviceability.

\section{Conclusions}

Evaluation of the effect of corrosion on the structural behavior of reinforced concrete pier wharf columns is essential for estimating the residual load-carrying capacity, and ultimately for the development of cost-effective repair strategies.

The following were the conclusions:

(i) The diameter of the steel rebars and confinement are two important factors that influence the specimen's bond strength behavior due to corrosion. The confined group had a higher bond strength than the unconfined group. The smaller reinforcement diameter $(16 \mathrm{~mm})$ had the highest corrosion level and lower bond strength in both groups than the larger reinforcement diameter $(20 \mathrm{~mm}$ and $25 \mathrm{~mm}$ )

(ii) The bond strength initially increases with an increase in the corrosion level until concrete cracks develop; then, the bond strength decreases with further increases in the corrosion level. Generally, the bond strength decreases as the corrosion level increases

(iii) There is an exponential relationship between the bond strength and the average crack width for the specimen without stirrups. In contrast, for samples with stirrups, the strength showed no reduction until the crack width reached $0.0060 \mathrm{~mm}$. Thus, the surface crack width is a better indicator of bond strength degradation than the average corrosion penetration

(iv) Confinement has a great advantage in the residual life of corroded-damaged structures.

\section{Recommendations}

It is recommended to study the reduction of the crosssectional area of prestressing wires due to corrosion, corrosion level, and the rate of its deteriorations.

\section{Data Availability}

The results of experimental data used to support the findings of this study are included within the article.

\section{Conflicts of Interest}

The authors declare no conflicts of interest.

\section{Acknowledgments}

ERDT-DOST funded the study in the School of Engineering at the University of San Carlos. The authors acknowledge the graduate scholarship funding from ERDT-DOST by the School of Engineering at the University of San Carlos.

\section{References}

[1] M. N. Hamidun, I. Nur'ain, M. N. Nurazuwa, S. Norliana, Z. Rozlin, and K. Narimah, "Structural effects of reinforced concrete beam due to corrosion. E3S Web of Conferences," CENVIRON, vol. 34, no. 2018, article 01024, 2018.

[2] M. Tapan and R. Aboutaha, "Effect of steel corrosion and loss of concrete cover on strength of deteriorated RC columns," Construction and Building Materials, vol. 25, no. 5, pp. 25962603, 2011.

[3] A. K. Azad, S. Ahmad, and S. A. Azher, "Residual strength of corrosion-damaged reinforced concrete beams," ACI Materials Journal, vol. 104, no. 1, pp. 40-47, 2007.

[4] F. Tondolo, "Bond behaviour with reinforcement corrosion," Construction and Building Materials, vol. 93, pp. 926-932, 2015.

[5] J. Bilcik and I. Holly, "Effect of reinforcement corrosion on bond behaviour," Procedia Engineering, vol. 65, no. 2013, pp. 248-253, 2013.

[6] A. Ouglova, Y. Berthaud, F. Foct, M. François, F. Ragueneau, and I. Petre-Lazar, "The influence of corrosion on bond properties between concrete and reinforcement in concrete 
structures," Materials and Structures, vol. 41, no. 5, pp. 969980, 2008.

[7] G. G. Triantafyllou, T. C. Rousakis, and A. I. Karabinis, "Analytical assessment of the bearing capacity of RC beams with corroded steel bars beyond concrete cover cracking," Composites Part B. Engineering, vol. 119, pp. 132-140, 2017.

[8] I. Fernandez, M. F. Herrador, A. R. Mari, and J. M. Bairan, "Ultimate capacity of corroded statically indeterminate reinforced concrete members," International Journal of Concrete Structures and Materials., vol. 12, no. 1, 2018.

[9] X. Zhang, X. Liang, Z. Wang, H. Huang, and H. Zhou, "An experimental study on effect of steel corrosion on the bondslip performance of reinforced concrete," in 5th International Conference on Durability of Concrete Structures, Shenzhen University, Shenzhen, Guangdong Province, P.R. China, June-July 2016.

[10] Y. Zhao and W. Jin, "Modeling the amount of steel corrosion at the cracking of concrete cover," Advances in Structural Engineering, vol. 9, no. 5, pp. 687-696, 2016.

[11] A. Kreit, F. Al-Mahmoud, A. Castel, and R. Francois, "Repairing Corroded RC beam with near-surface mounted CFRP rods," Materials and Structures, vol. 44, no. 7, pp. 1205-1217, 2011.

[12] J. Joshi, H. Arora, and U. Sharma, "Structural performance of differently confined and strengthened corroding reinforced concrete columns," Construction and Building Materials, vol. 82, pp. 287-295, 2015.

[13] J. Cabrera, "Deterioration of concrete due to reinforcement steel corrosion," Cement and Concrete Composites, vol. 18, no. 1, pp. 47-59, 1996.

[14] Y. Zhao, H. Lin, K. Wu, and W. Jin, "Bond behaviour of nor$\mathrm{mal} /$ recycled concrete and corroded steel bars," Construction and Building Materials, vol. 48, pp. 348-359, 2013.

[15] H. Chen and J. Nepal, "Analytical model for residual bond strength of corroded reinforcement in concrete structures," Journal of Engineering Mechanics, vol. 142, no. 2, article 04015079, 2015.

[16] F. Li and Y. Yuan, "Effects of corrosion on bond behavior between steel strand and concrete," Construction and Building Materials, vol. 38, pp. 413-422, 2013.

[17] S. Sotoud, Effect of severe corrosion on lateral strength of square RC bridge columns, Syracuse University, 2016, http://surface .syr.edu/etd.

[18] A. Castel, I. Khan, R. Francois, and R. I. Gilbert, "Modeling Steel Concrete bond strength reduction due to corrosion," ACI Structural Journal, vol. 113, no. 5, pp. 973-982, 2016.

[19] A. H. Al-Saidy, A. S. Al-Harthy, K. S. Al-Jabri, M. AbdulHalim, and N. M. Al-Shidi, "Structural performance of corroded RC beams repaired with CFRP sheets," Composite Structures, vol. 92, no. 8, pp. 1931-1938, 2010.

[20] G. G. Triantafyllou, T. C. Rousakis, and A. I. Karabinis, "Effect of patch repair and strengthening with EBR and NSM CFRP laminates for RC beams with low, medium and heavy corrosion," Composites Part B: Engineering, vol. 133, pp. 101-111, 2018.

[21] G. G. Triantafyllou, T. C. Rousakis, and A. I. Karabinis, "Corroded RC beams patch repaired and strengthened in flexure with fiber- reinforced polymer laminates," Composites Part B Engineering, vol. 112, no. 2017, pp. 125-136, 2017.
[22] H. Lin, Y. Zhao, J. Ožbolt, and H. Reinhardt, "Bond strength evaluation of corroded steel bars via the surface crack width induced by reinforcement corrosion," Engineering Structures, vol. 152, pp. 506-522, 2017.

[23] A. Kivell, A. Palermo, and A. Scott, "Effects of bond deterioration due to corrosion in reinforced concrete," Proceedings of the North Pacific Conferences on Earthquake Engineering. Building an Earthquake-Resilinet Society, 2011, Auckland, New Zealand, April 2011, 2011. 